\title{
NBSIR 74-451
}

\section{Field Comparisons of Steel Surveyors' Tapes}

C. Leon Carroll, Jr.

Institute for Basic Standards

National Bureau of Standards

Washington, D. C. 20234

November 1973

Final

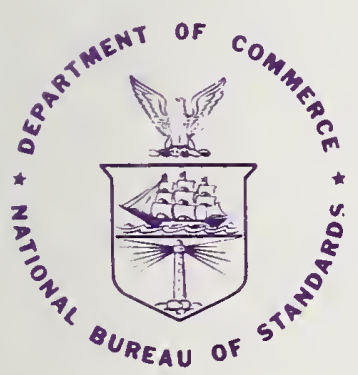

U. S. DEPARTMENT OF COMMERCE

NATIONAL BUREAU OF STANDARDS 



\section{FIELD COMPARISONS OF STEEL} SURVEYORS' TAPES

C. Leon Carroll, Jr.

Institute for Basic Standards

National Bureau of Standards

Washington, D. C. 20234

November 1973

Final

U. S. DEPARTMENT OF COMMERCE. Froderick B. Dent, Socretary NATIONAL BUREAU OF STANDARDS, Richard $w$. Roberts. Director 
- in

$\therefore ?$ 


\section{Fleld Comparisons of Steel Surveyors' Tapes}

C. Ieon Carroll, Jr.

The accuracy of a surveyor's measurement must often be provable to $100 \mathrm{ppm}$ (sometimes in a court of law) and a significant feature of such proof is his knowledge of his tape length under specified conditions. This paper describes a technique which will provide such knowledge. The technique is an easily performed comparison between his tape and a calibrated standard tape (perhaps borrowed from a State Weights and Measures Laboratory). This scheme has been tried out at the National Bureau of Standards under a number of conditions likely to be encountered in the field, and the results of these tests did not differ significantly from a comparison in our tape laboratory conducted under ideal conditions and using state-of-the-art apparatus. Traceability to NBS is established by the calibration genealogy of the standard tape.

A calibration activity measures and certifies the actual length of the standard tape at $68^{\circ} \mathrm{F}$ under ten pounds tension. Given access to such a standard tape, the surveyor may determine the actual length of his own tape. Although his experiment will not necessarily be conducted at $68^{\circ} \mathrm{F}$, his data will reflect length at $68^{\circ} \mathrm{F}$ to an accuracy appropriate to $100 \mathrm{ppm}$ survey work if his tape and the standard tape have similar thermal, elastic and geometric properties. These required conditions exclude a comparison between a steel and an invar tape because of grossly different thermal properties. The surface finishes of the tapes should be similar if the comparison is made in the direct sunlight.

The comparison experiment, shown schematically by the sketch on the specimen data sheet, figure 1 , consists of measuring the difference in lengths between the standard and test tapes. If the certified length of the standard tape is $S$, and A, B, C and D the measurements indicated on the sketch, then the length of the test tape, $L$, at $68^{\circ} \mathrm{F}$ under the tension applied during the comparison is given by

$$
L=S+[A-B-C+D] K
$$

where $K$ is the coefficient relating the units of the small end scales to the tape units ( 1 Foot $=304.8$ millimeters).

The details of the experimental setup are shown in figures 3 and 4. No effort should be made to align the ends of the two tapes to coincidence. However, keep the tapes as close to the end scales as possible to reduce reading errors due to parallax. Graph paper 
placed directly under the tapes is superior. Experience has shown that residual errors associated with failure to achieve perfect coincidence are larger than those associated with measurements of lack of coincidence. Millimeter graduations on the small end scales are far more practical than any other cormonly used graduation interval (e.g. 64ths or 10ths of an inch). This is because the normal eye can estimate to $1 / 10$ of a millimeter with an assurance of about 0.15 millimeter using a low-power handheld magnifier. The errors injected into the overall comparison experiment by the imperfections in inexpensive millimeter scales are insignificant in this experiment. The end scale requirements are:

(1) That the graduations of the two edges of the small scale start at a cormon "zero."

(2) That the small end scales will be required to measure a distance of no more than about an inch by insuring that the end point graduations on the two tapes are separated by no more than about an inch along their lengths.

(3) For convenience of observation (estimating $1 / 10 \mathrm{~mm}$ ) the thickness of the graduation lines be no more than about 1/10 the graduation interval. Good quality graph paper satisfies this requirement adequately.

Survey measurements to 100 ppm allow for errors of 0.12 inch per hundred feet. Although it is unlikely that errors of as much as one-third of this allowance could occur in the comparison experiment, good practice demands a redundancy of measurements. The specimen data sheet (figure 1) requires three independent measurements of the difference between the two tape lengths. Requirements are satisfied by moving both end scales after a round of observations on $A, B, C$ and $D$.

If the surveyor customarily makes only one field measurement of a distance (for example, from a bench mark to a fence), then the comparison experiment is adequately performed by filling out and calculating one data sheet (i.e. three determinations). On the other hand, if his customary practice is to make the measurement twice and report the average value, then he should fill out two data sheets and use the average of the two values of $L$ obtained thereby.

As pointed out above, the certified value, $S$, of the standard tape refers to its length at $68^{\circ} \mathrm{F}$ and ten pounds tension. The similarity between the thermal properties (that is, the temperature 
coefficients of expansion of the two tapes) eliminates the requirement to conduct the experiment at $68^{\circ} \mathrm{F}$. The tension applied to the two tapes, however, must be carefully measured. The tension in the standard tape must be ten pounds inasmuch as this is the certification tension. our experimental setup is shown in figures 3 and 4. It is noted that we also used a spring balance (checked as shown in figure 2) to tension our test tape to the ten pound level, however, this is not required. The comparison experiment is perfectly valid regardless of the tension, Q, applied to the test tape. The surveyor may apply any amount by any tensioning device of his choice. Inasmuch as the value of $\mathrm{L}$ (calculated above) is valid only at tension $Q$, the surveyor will normally stretch his tape to a tension of $Q$ during practical field measurements.

There are times at which the surveyor will prefer to stretch his tape to the "tension of accuracy," $\mathrm{Q}_{A}$. This is the amount of tension which causes his tape to assume a length of "exactly" 100 feet at the tape temperature during the field measurement. $Q_{A}$ at tape temperature $\mathrm{T}$ may be calculated from an algebraic combination of $\mathrm{Q}$ and $I$ (as determined in the comparison test) with $\alpha$ and AE (two of the constants associated with the tape and obtainable from the manufacturer)

$$
Q_{A}=Q+A E[1-0.01(L)-\alpha(T-68)]
$$

where $\alpha$ is the temperature coefficient of expansion of the tape in feet per foot per degree $F$, and $A E$ is the effective product in pounds force of Young's modulus of elasticity of the tape by its cross section area.

From years of experience we have found that .00000645 is an adequate value for $\alpha$ of steel tapes. The surveyor may check the manufacturer's estimate of the AE product by a simple extension of the comparison experiment. From the initial experiment he has determined that a value of $L$ exists at a tension of $Q$. He must now determine, from a second comparison, a second value of $L$, namely $L_{1}$, which exists when the test tape is stretched by a tension of $Q_{1}$. The tension of the standard tape remains at ten pounds during both comparisons. Ordinarily, $Q_{1}$, should be about ten pourids greater than $Q$. From $Q, Q_{1}, L$ and $L_{1}$ he may calculate $A E$.

For example, suppose the surveyor has found that at $Q=10$ pounds, $I=99.998_{4}$ feet. This is illustrated in figure 5 showing an actual NBS comparison experiment conducted on an asphalt driveway. If a second comparison (conducted at $Q_{1}=20$ pounds) yielded a value of $\mathrm{L}_{1}=100.006$, then

$$
A E=\frac{\left(Q_{1}-Q\right) 100}{L_{1}-L}=132,000 \text { pounds (force) }
$$

which is in adequate with the manufacturer's estimate. 
It should be carefully noted that $T$ in the formula for $Q_{A}$ is the temperature of the tape. If the tape is shielded from the direct rays of the sun, the ambient air temperature may be used without unacceptable errors in $Q_{A}$. If the tape is exposed to the direct sunlight, the actual tape temperature may be thirty or more degrees Fahrenheit above ambient, in which case the tape temperature must be measured by a tape thermometer (obtainable from tape manufacturers). We have found that a mercury thermometer covered by a surface similar to that of the tape will indicate a temperature approximating that of the tape. Thus, black friction tape (for use with a black measuring tape), or white filament type tape (for use with a white measuring tape) will force a mercury thermometer to approximate the measuring tape temperature. In direct sunlight we have found a $15^{\circ} \mathrm{F}$ difference in the temperature of a black tape (hotter) and a white one (colder) with bare stainless steel and bare brass between these two extremes. Our measurements were made in the summer $\left(75-85^{\circ} \mathrm{F}\right.$ ambient), and these radiant effects are probably much greater during the winter in a cold ambient.

For tapes longer than 100 feet, each 100 foot interval may be compared as described above. It should be mentioned that each such interval should be subjected to the same test tension, Q.

Flgures 5, 6, 7 and 8 show the results of comparisons between the same two tapes under various conditions likely to be encountered in the field. The results are tabulated on the following page, all values referring to a ten pound tension on the test tape. 

EXIERNAL CONDITIONS
Asphalt parking lot and driveway with a $5 \%$ grade in bright sunlight.

On grass alongside brick building -mostly shade, some sun.

On cement platform of truck scale and extending through doors to outside of scale house on cement approach.

On vinyl tile hallway in basement of Metrology Building.

Comparison conducted in tape laboratory under ideal controlled conditions.
ANBIENT

TEMP

TAPE LENGTH

RAW DATA

$88^{\circ} \mathrm{F} \quad 99.998_{4}$ ft. $\quad$ Fig. 5

$82^{\circ} \mathrm{F} \quad 100.0002$ ft. $\quad$ Fig. 6

$78^{\circ} \mathrm{F} \quad 99.998_{4}$ ft. $\quad$ Fig. 7

$72^{\circ} \mathrm{F} \quad 99.999-2^{\mathrm{ft} .} \quad$ Fig. 8

Not

$68^{\circ} \mathrm{F} \quad 99.999 \mathrm{ft}$ Show

The spread of field data is $.001_{8}$ feet, or about 20 ppm, all points being in good agreement with the laboratory experiment.

While the completed data sheet is normally adequate, it may be required to provide further documentation. The following wording is suggested:

"This is to certify that the tape (manufacturer, serial number, type) marked (see below) has been tested in accordance with the procedure outlined in NBSIR Report No. 73-408. These tests were conducted with reference to a standard tape owned by (owner) which was calibrated by the National Bureau of Standards under Test Number

The length of the tape tested was found to be feet under pounds tension at $68^{\circ} \mathrm{F}$ with the tape supported throughout its length." 
This report should be dated and signed by the surveyor (or some other designated person in the organization). The supporting data should be retained on file. If it is felt that tested tapes should be marked for identification, suitable marking can be done with etching ink commercially available.

US COMM-NBS-DC 
OBSERVED DATA AND CALCULATIONS OF THE LENGTH (L) OF A STEEL SURVEYOR TAPE AT $68^{\circ} \mathrm{F}$ BASED ON A FIELD COMPARISON TO A CALIBRATED STANDARD TAPE

DATE TIME

AIR TEMP SKY/WEATHER

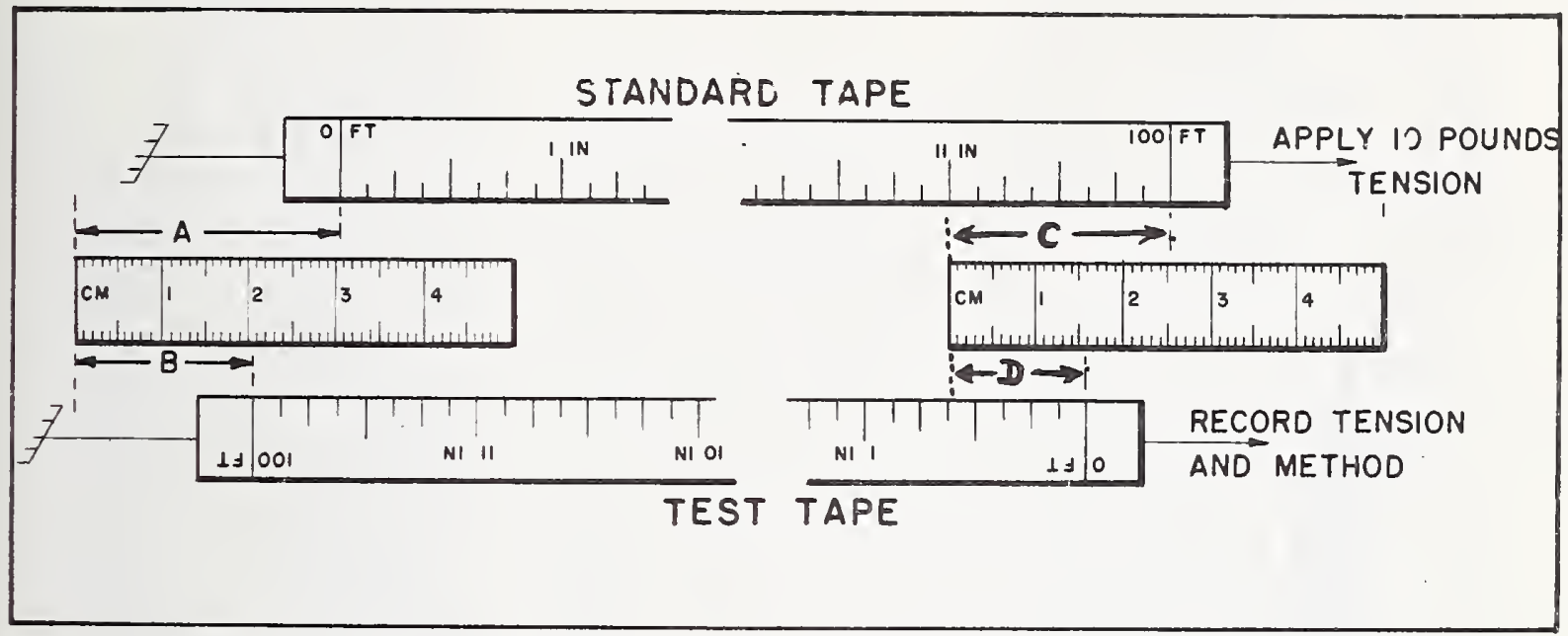

STANDARD TAPE

TEST TAPE

Manufacturer Serial

Manufacturer Serial

Temp.Coef。Exp。 $=\alpha=$ $\mathrm{FT} / \mathrm{FT} /{ }^{\circ} \mathrm{F}$

Temp. Coef. Exp $:=\alpha=$ $\mathrm{FT} / \mathrm{FT} /{ }^{\circ} \mathrm{F}$ $\mathrm{WT} / \mathrm{FT}=\mathrm{W}=$ LBS $A E=$ LBS $\mathrm{WT} / \mathrm{FT}=\mathrm{W}=$ LBS $\quad A E=$ LBS Material/Color/Finish

Certified Length at $68^{\circ} \mathrm{F}$ Under a Tension of 10 pounds $(S=)$

feet Tension Method

Material/Color/Finish

Applied Tension POUNDS

Observed Data (in cms)

A

B
C
D

$(A-B-C+D) *$

First Trial

Second Trial

Third Trial

$$
\Sigma A=
$$
$\Sigma B=$

$\Sigma \mathrm{C}=$ $\Sigma D=$

$$
L=S+.010936[\Sigma A-\Sigma B-\Sigma C+\Sigma D]=
$$
feet

*This is a check calculation. In the absence of gross blunders these three values would normally differ by no more than about 0.15 .

REMARKS (Show calibration genealogy of the standard tape and describe conditions surrounding comparison). 


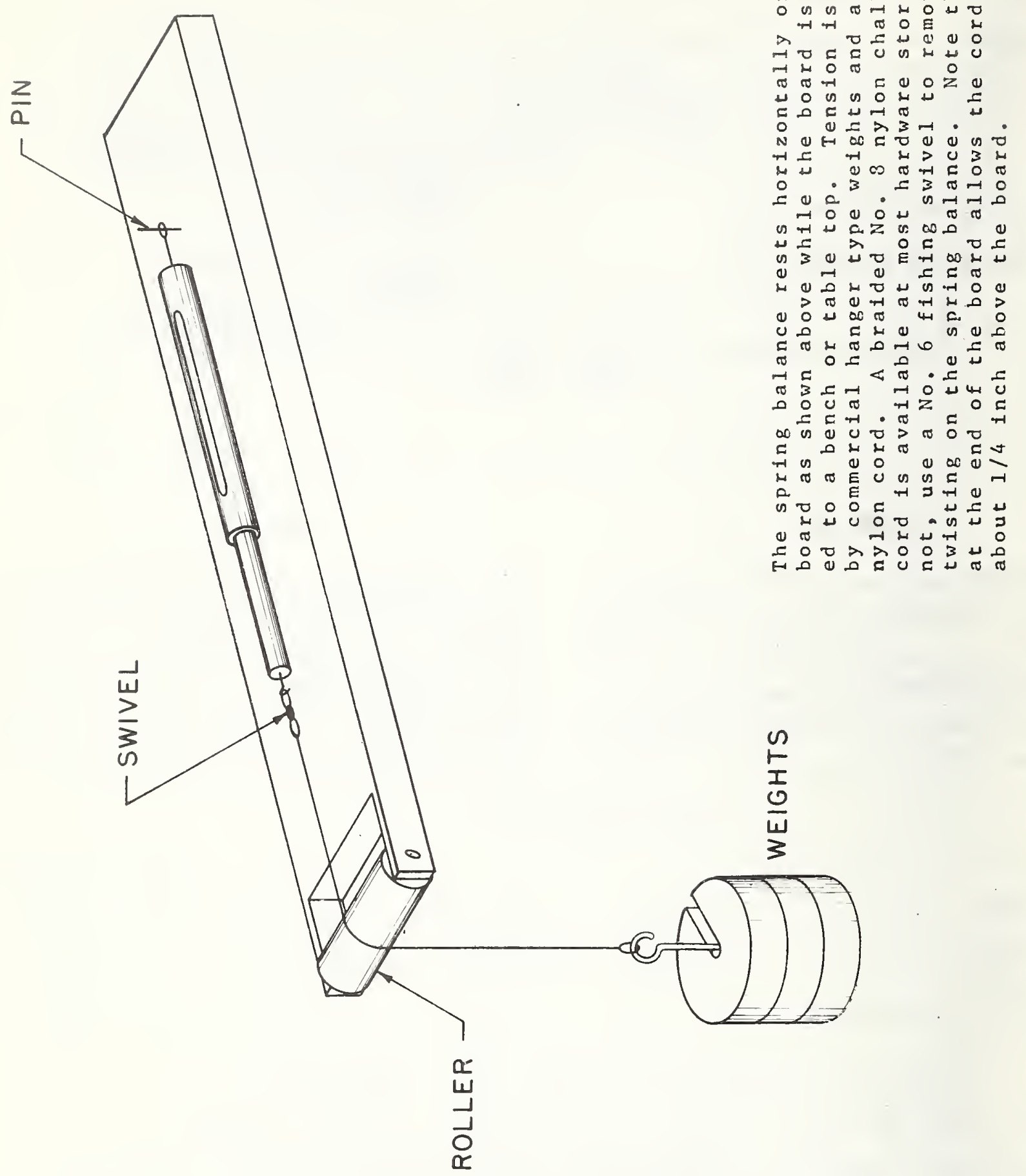

v 


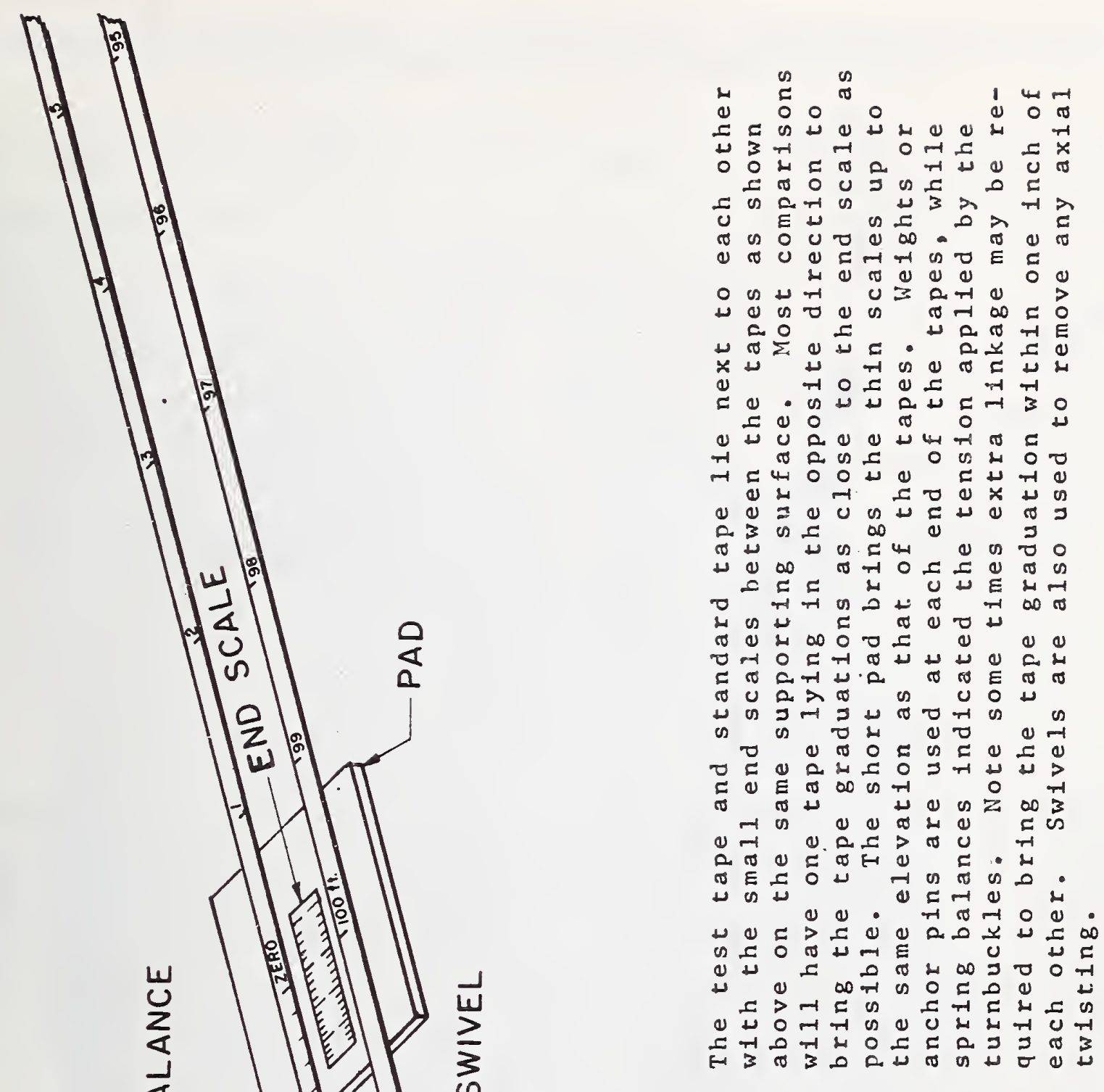




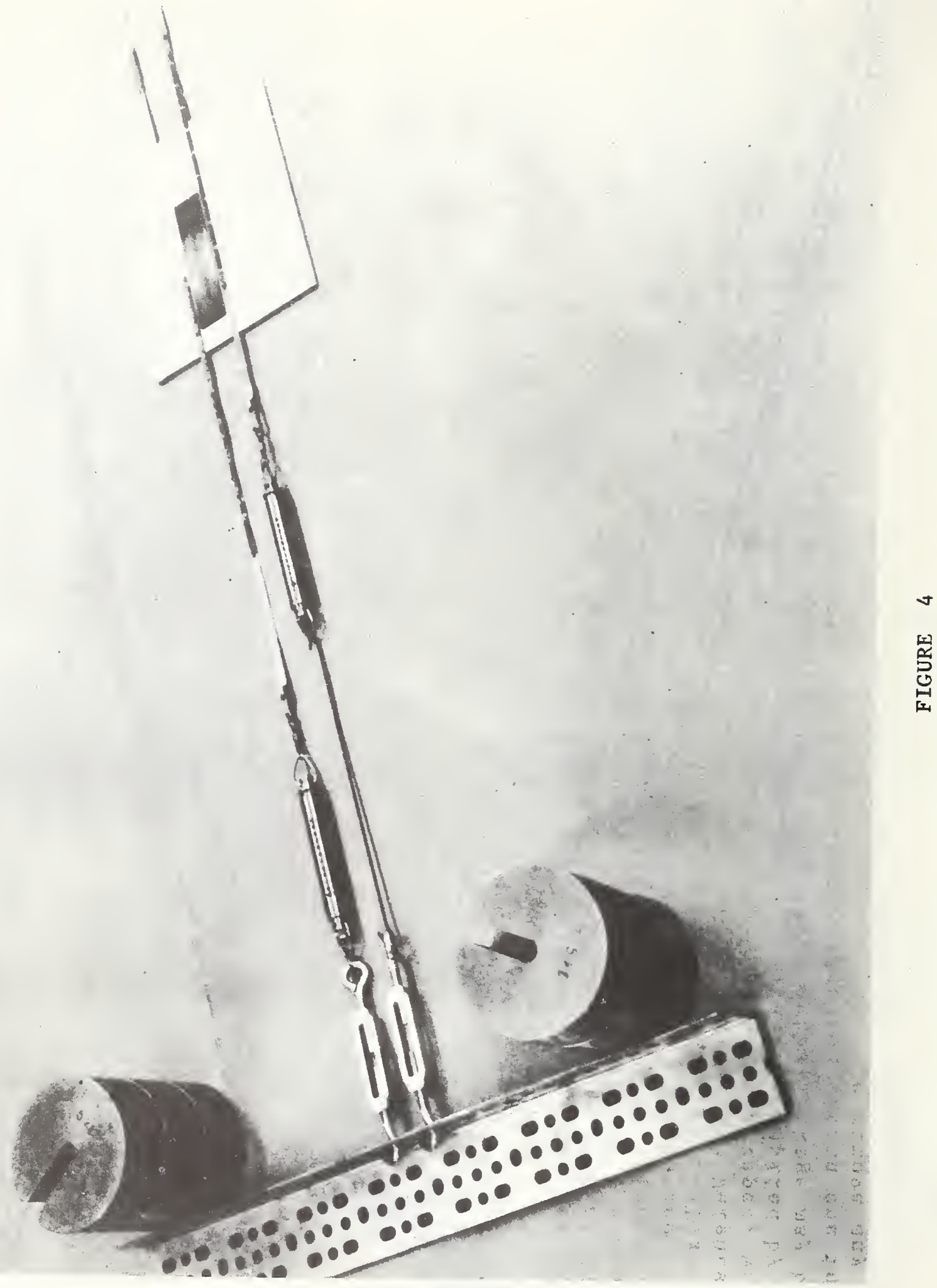


OBSERVED DATA AND CALCULATIONS OF THE LENGTH (L) OF A STEEL SURVEYOR TARE AT $68^{\circ} \mathrm{F}$ BASED ON A FIELD COMPARISON TO A CALIBRATED STANDARD TAPE

DATE $7-18-70 \mathrm{TIME} 10^{45 / \mathrm{AM}}$ AIR TEMP_ 88 SKY/WEATHER_CCEAP

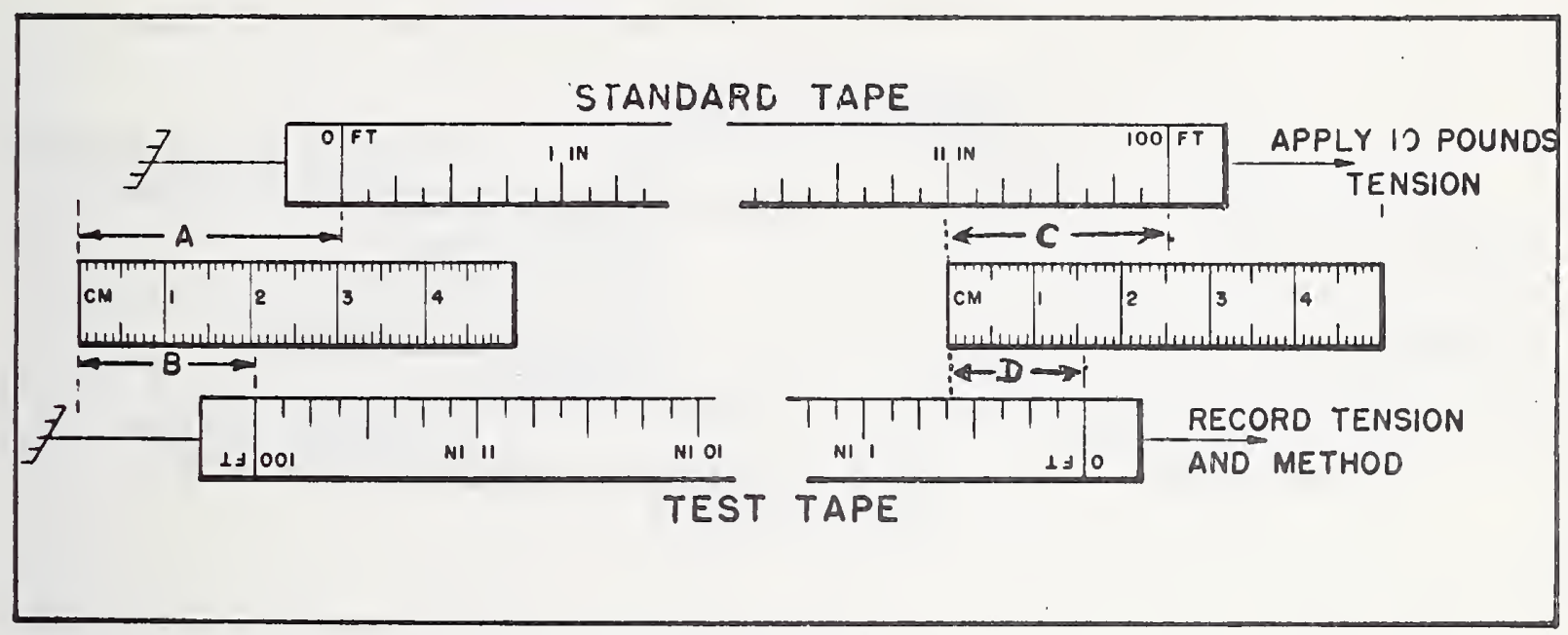

STANDARD TAPE

TEST TAPE

Manufacturer

Serial

Manufacturer Serial

Temp. Coef.Exp. $=\alpha=0.00000645 \mathrm{FT} / \mathrm{FT} /{ }^{\circ} \mathrm{F}$ $\mathrm{WT} / \mathrm{FT}=\mathrm{W}=0.01 \mathrm{H7}$ LBS $\mathrm{AE}=128000$ LBS Material/Color/Finish STEEL BLACK CLCSS Certified Length at $68^{\circ} \mathrm{F}$ Under a Tension of 10 pounds $(\mathrm{S}=)$ feet Temp. Coef.Exp. $E \alpha=0.00000645 \mathrm{FT} / \mathrm{FT} /{ }^{\circ} \mathrm{F}$ $\mathrm{WT} / \mathrm{FT}=\mathrm{W}=0.0142$ LBS $\mathrm{AE}=125000$ LBS Material/Color/Finish STEEL BCACK CLES Applied Tension POUNDS

Tension Method SPPINE BALANCE Observed Data (in cms)

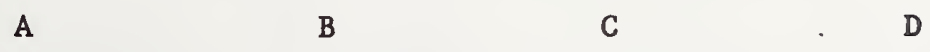

$\begin{array}{lll}\text { First Trial } & \frac{2.11}{2.29} & \frac{1.94}{2,13} \\ \text { Second Trial } & \frac{2.29}{1.97} & \frac{1.83}{\text { Third Trial }}\end{array}$

$\Sigma A=6.37 \quad \Sigma B=5.90$

$L=S+.010936[\Sigma A-\Sigma B-\Sigma C+\Sigma D]=$

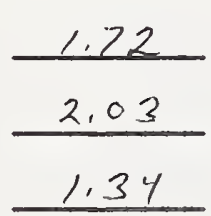

$\frac{1.48}{1.81}$

$(A-B-C+D) *$

*Th1s is a check calculation. In the absence of gross blunders these three values would normally differ by no more than about 0.15 .

REMARKS (Show calibration genealogy of the standard tape and describe conditions surrounding comparison).

on Asphalt Parkine lot and DAIVENAY with $5 \%$ crade

FIGURE 5

OBSERVER C C $\angle C$ \& FE. 
OBSERVED DATA AND CALCULATIONS OF THE LENGTH (L) OF A STEEL SURVEYOR TAPE AT $68^{\circ} \mathrm{F}$ BASE. ON A FIELD COMPARISON TO A CALIBRATED STANDARD TAPE

DATE $2-15-70 \mathrm{TIME}, 10 / \mathrm{pm}$ AIR TEMP_ $82 \quad$ SKY/WEATHER CLEAT (IN SHADE)

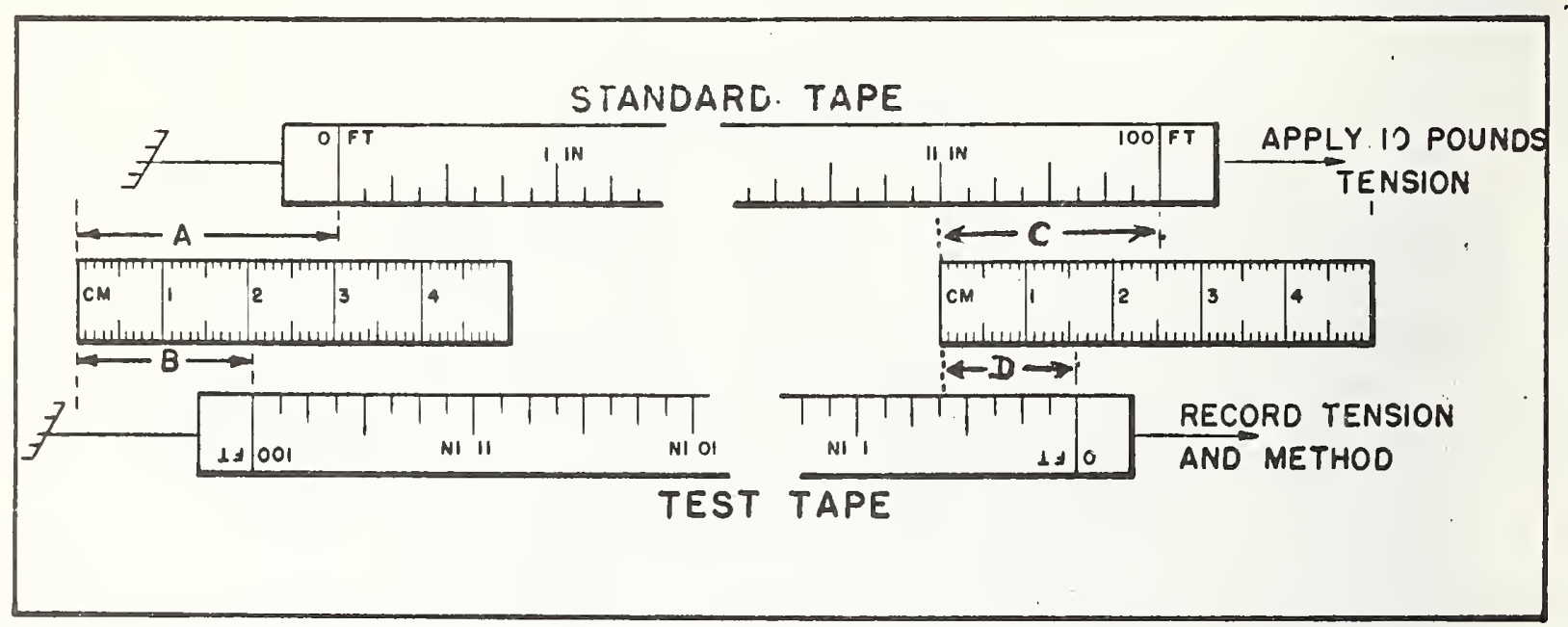

STANDARD TAPE

Manufacturer Serial

Temp.Coef.Exp. $\approx \alpha=0.00000645 \mathrm{FT} / \mathrm{FT} /{ }^{\circ} \mathrm{F}$ $\mathrm{WT} / \mathrm{FT}=\mathrm{W}=0,0147$ LBS $\mathrm{AE}=128000$ LBS Material/Color/Finish STEEL, BLACK, Eiñ Certified Length at $68^{\circ} \mathrm{F}$ Under a Tension of 10 pounds $(S=)$ 100,001 feet
TEST TAPE

Manufacturer Serial

Temp.Coef.Exp. $\approx \alpha=0.00000645$ $\mathrm{FT} / \mathrm{FT} /{ }^{\circ} \mathrm{F}$ $\mathrm{WT} / \mathrm{FT}=\mathrm{W}=0.0142$ LBS $\mathrm{AE}=125000$ LBS Material/Color/Finish STEEL. DiACK, Giars Applied Tension POUNDS SPRINE BALANCE

Observed Data (in cms)

A

First Trial

Second Trial

Third Trial

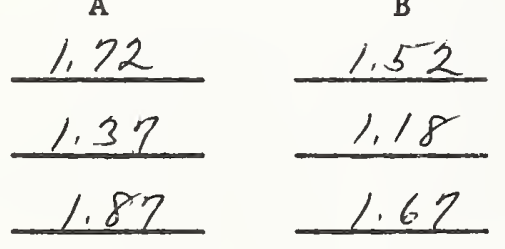

C

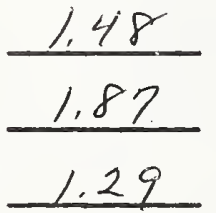

D

$\frac{1.26}{1.63}$

$(A-B-C+D) *$

$\frac{-0.0 .2}{-0.05}$

$\Sigma A=4.96 \quad \Sigma B=4.32 \quad \Sigma C=4.64 \quad \Sigma D=3.96$

$\mathrm{L}=\mathrm{S}+.010936[\Sigma \mathrm{A}-\Sigma \mathrm{B}-\Sigma \mathrm{C}+\Sigma \mathrm{D}]=$ $100.000_{2}$ feet

*This is a check calculation. In the absence of gross blunders these three values would normally differ by no more than about 0.15 .

REMARKS (Show calibration genealogy of the standard tape and describe conditions surrounding comparison).

ON ERASS AT SHADY SIDE OF BUILDING AND ONE END OF

TAPE IN BRIEHT SANLIEHT 
OBSERVED DATA AND CALCULATIONS OF THE LENGTH (L) OF A STEEL SURVEYOR TAPE AT $68^{\bullet} \mathrm{P}$ BASED ON A FIELD COMPARISON TO A CALIBRATED STANDARD TAPE

DATE 7-15-70 TIME_910/M AIR TEMP_ 28_ SKY/WEATHER_CEAT

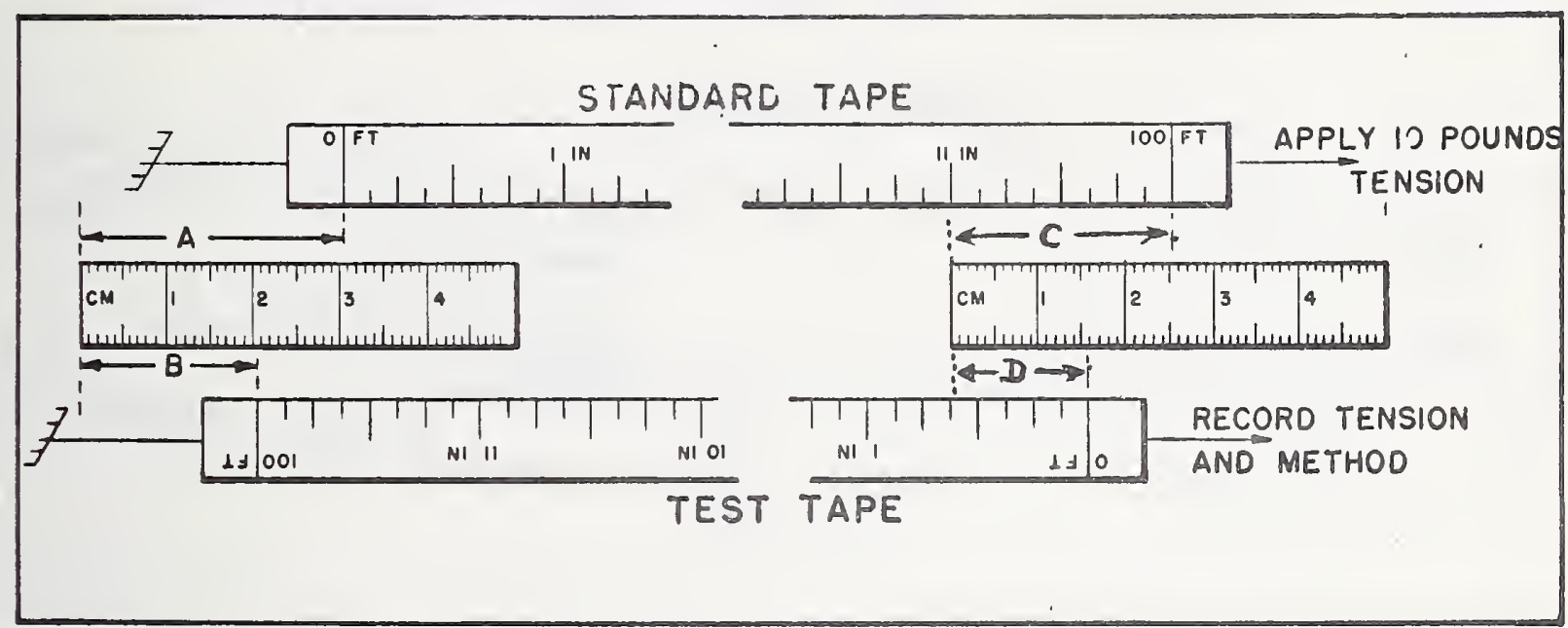

STANDARD TAPE

TEST TAPE

Manufacturer

Serial

Temp.Coef.Exp. $=\alpha=0.00000645 \mathrm{FT} / \mathrm{FT} /{ }^{\circ} \mathrm{F}$

WT $/ \mathrm{FT}=\mathrm{W}=0.0147 \mathrm{LBS} \quad \mathrm{AE}=128000 \mathrm{LBS}$

Material/Color/Finish STEEL, BLACK, CLOSS

Certified Length at $68^{\circ} \mathrm{F}$ Under a Tension of 10 pound $s(S=)$ feet
Manufacturer

Temp. Coef. $\operatorname{Exp} .=\alpha=0.00000645 \mathrm{RT} / \mathrm{FT} /{ }^{\circ} \mathrm{F}$ $\mathrm{WT} / \mathrm{FT}=\mathrm{W}=0,0142$ LBS $\mathrm{AE}=125000$ LBS Material/Color/Finish STEEL, B.ACK, CLUS Applied Tension Tension Method POUNDS SPRINE BALANCE Observed Data (in cms)

A B C C D

First Trial

Second Trial

Third Trial

$\Sigma A=5.03 \quad \Sigma B=4.42 \quad \Sigma C$

$L=S+.010936[\Sigma A-\Sigma B-\Sigma C+\Sigma D]=$

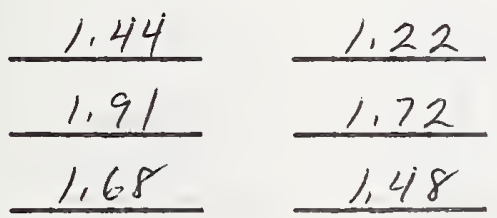

2.49

$2 \cdot 21$

2.08

1,79

1.83
$(A-B-C+D) *$

$-0.06$

$-0,10$

$-0.08$

*This is a check calculation. In the absence of gross blunders these three values would normally differ by no more than about 0.15 .

REMARKS (Show calibration genealogy of the standard tape and deacribe conditions surrounding comparison).

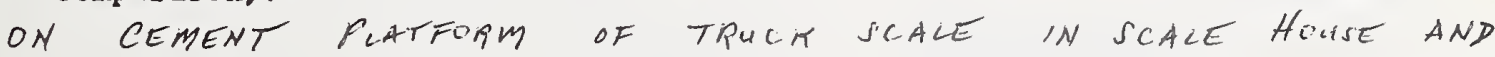

TAPES EXTENDING THPOUEH DUOR TO OUTSIDE APPPCACH RAMP.

FIGURE 7

OBSERVER CLC, o F,E,S. 
OBSERVED DATA AND CALCULATIONS OF THE LENGTH (L) OF A STEEL SURVEYOR TAPE AT $68^{\circ} \mathrm{B}$ BAin.." ON A FIELD COMPARISON TO A CALIBRATED STANDARD TAPE

DATE 7-14-70 TIME $10^{05} / \mathrm{Am}$ AIR TEMP 72 SKY/WEATHER INSIDE B Be

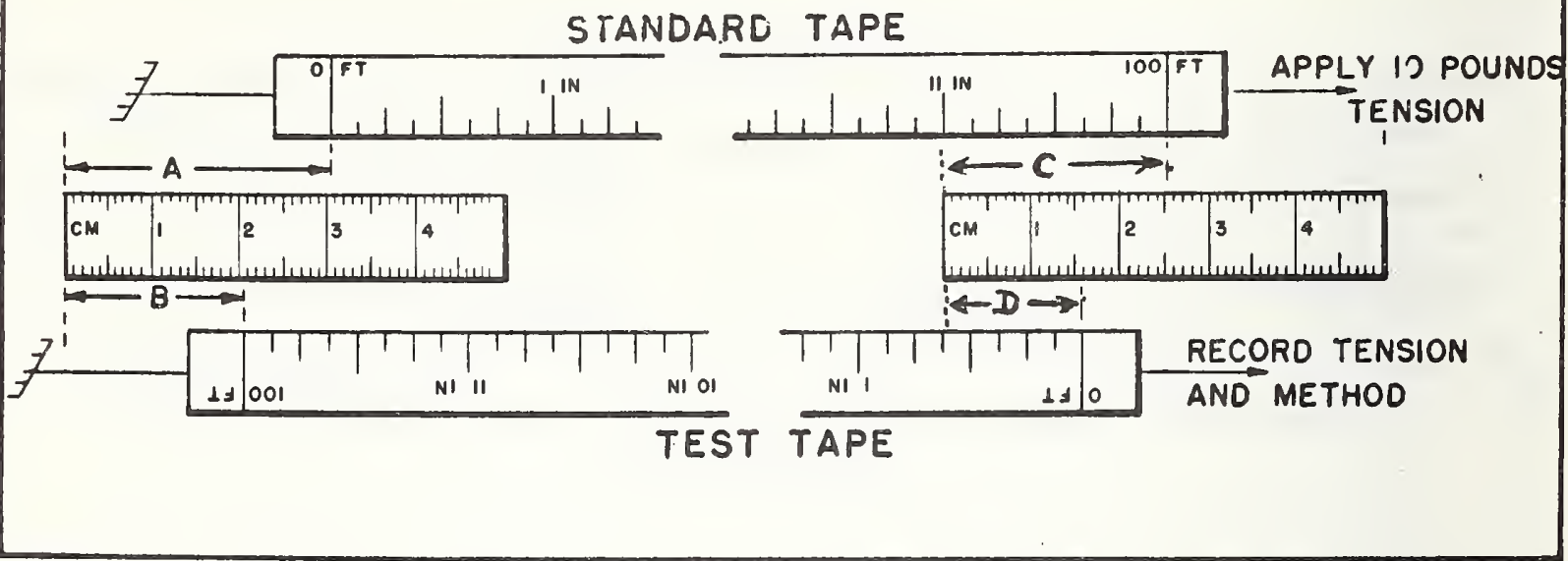

STANDARD TAPE

Manufacturer Serial

Temp.Coef.Exp. $\approx \alpha=0.00000645 \mathrm{FT} / \mathrm{FT} /{ }^{\circ} \mathrm{F}$ $\mathrm{WT} / \mathrm{FT}=\mathrm{W}=0,0147$ LBS $\mathrm{AE}=128000 \mathrm{LBS}$ Material/Color/Finish STEEL,BLACK, ELOS Certified Length at $68^{\circ} \mathrm{F}$ Under a Tension of 10 pounds $(\mathrm{Sm})$ 100,001 feet
Manufacturer

\section{TEST TAPE}

Temp.Coef.Exp. $=0.00000645 \mathrm{FT} / \mathrm{FT} /{ }^{\circ} \mathrm{F}$ $\mathrm{WT} / \mathrm{FT}=\mathrm{W}=0.0142$ LBS $\mathrm{AE}=125.000$ LBS Material/Color/Finish_5TEEL, BLACK, GLIS Applied Tension 10 POUNDS Tension Method SPPINE BALANCE

Observed Data (in cms)

\begin{tabular}{|c|c|c|c|c|c|}
\hline First Trial & 1.41 & $\begin{array}{r}8 \\
1.25 \\
\end{array}$ & $\begin{array}{c}c \\
1.89 \\
\end{array}$ & $\begin{array}{r}D \\
1.64 \\
\end{array}$ & $\begin{array}{c}(A-B-C+D) * \\
-0.09 \\
\end{array}$ \\
\hline Second Trial & 1.52 & 1.37 & 1.51 & 1.22 & -0.09 \\
\hline Third Trial & 1,87 & 1.66 & 1.80 & 1.57 & -0.02 \\
\hline
\end{tabular}
$\Sigma A=4.80 \quad \Sigma B=4.28 \quad \Sigma C=4.20 \quad \Sigma D=4.48$ $L=S+.010936[\Sigma A-\Sigma B-\Sigma C+\Sigma D]=$ $99.999_{-2}$ feet

*This is a check calculation. In the absence of gross blunders these three values would normally differ by no more than about 0.15 .

REMARKS (Show calibration genealogy of the standard tape and describe conditions surrounding comparison).

ON VINYL TILE FLOOR IN BASEMENT 


\begin{tabular}{|c|c|c|c|}
\hline $\begin{array}{l}\text { U.S. DEPT. OF COMM. } \\
\text { BIBLIOGRAPHIC DATA } \\
\text { SHEET }\end{array}$ & $\begin{array}{l}\text { 1. PUISLICATION OR REPORT NO. } \\
\text { NBSIR 73-408 }\end{array}$ & $\begin{array}{l}\text { 2. Gov't Accession } \\
\text { No. }\end{array}$ & 3. Recipient's Acecession No. \\
\hline 4. TITLE AND SURTITLE & aricons of Stopl Sumyerong & & $\begin{array}{l}\text { 5. Publication Datc } \\
\text { November } 1973\end{array}$ \\
\hline \multicolumn{3}{|c|}{ Field Comparisons of Steel Surveyors' Tapes } & 6. Performing Organization Code \\
\hline \multicolumn{3}{|c|}{ 7. AUTHOR(S) C. Leon Camroll, Jr. } & $\begin{array}{l}\text { 8. Performing Organ. Report No. } \\
\text { NBSIR 73-408. }\end{array}$ \\
\hline \multicolumn{3}{|c|}{ 9. PER FORMING ORGANIZATION NAME AND ADDRESS } & 10. Project/Task/Work Unit No. \\
\hline \multicolumn{3}{|c|}{$\begin{array}{l}\text { NATIONAL BUREAU OF STANDARDS } \\
\text { DEPARTMENT OF COMMERCE } \\
\text { WASH!NGTON, D.C. } 20234\end{array}$} & 11. Contract/Grant No. \\
\hline \multirow{2}{*}{\multicolumn{3}{|c|}{ 12. Sponsoring Organization Name and Complete Address (Street, City, State, ZIP) }} & $\begin{array}{l}\text { 13. Type of Report \& Period } \\
\text { Covered }\end{array}$ \\
\hline & & & 14. Sponsoring Agency Code \\
\hline \multicolumn{4}{|l|}{ 15. SUPPLEMENTARY NOTES } \\
\hline
\end{tabular}

16. ABSTRACT (A 200-word or less factual summary of most significant in formation. If document includes a significant bibliography or literature survey, mention it here.)

Report describes a field procedure to compare a steel surveyor's tape to a standard tape that has been calibrated by The National Bureau of Standards. The procedure requires only a hand-held magnifier, two short scales, and two spring balances. Temperature reading device is not required since both tapes are made of steel and have the same temperature during the comparison.

17. KEY WORDS (six to twelve entries; alphabetical order; capitalize only the first letter of the first key word unless a proper name; separated by semicolons)

Graduation; length; scale; tape; temperature; tension.

18. AVAILABILITY $\sqrt{\mathrm{X}}$ Unlimited

ए For Official Distribution. Do Not Release to NTIS

$\square$ Order From Sup. of Doc., U.S. Government Printing Office Washington, D.C. 20402, SD Cat. No. C13

\begin{tabular}{|l|c|}
\hline $\begin{array}{l}\text { 19. SECURITY CLASS } \\
\text { (THIS REPURT) }\end{array}$ & 21. NO. OF PAGES \\
UNCL ASSIFIED & \\
\hline $\begin{array}{l}\text { 20. SECURITY CLASS } \\
\text { (THIS PAGE) }\end{array}$ & 22. Price \\
UNCLASSIFIED & \\
\hline
\end{tabular}

$\square$ Order From National Technical Information Service (NTIS) Springfield, Virginia 22 I 5 I 
. 


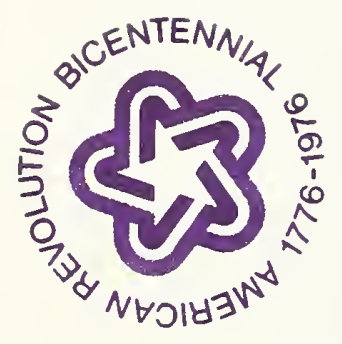

